\title{
Studi Fenomenologi: Pengalaman Koping Pada Pasien Kanker Serviks
}

\section{Hernandia Distinarista}

Fakultas Ilmu Keperawatan, Universitas Islam Sultan Agung Semarang

\begin{tabular}{ll}
\hline \multicolumn{1}{c}{ Article Info } & \multicolumn{1}{c}{ Abstract } \\
\cline { 2 - 3 } $\begin{array}{l}\text { Article History: } \\
\text { Accepted May 23rd } 2019\end{array}$ & $\begin{array}{l}\text { A cancer diagnosis not only affects patients but also family and friends. It is } \\
\text { not uncommon for patients to feel anxious, scared and stressed when they } \\
\text { hear the word "cancer" when the doctor presents the results of his analysis. } \\
\text { Key words: }\end{array}$ \\
$\begin{array}{l}\text { Each patient will respond differently and each will handle it in a different } \\
\text { way and this is determined by the coping mechanism of the individual. } \\
\text { Cancer patients need information, service, and care professionals in order to } \\
\text { lead a quality life. This study was designed to explore coping experiences in } \\
\text { cervical cancer patients. This study used a hermeneutic phenomenology } \\
\text { method, involving five participants in Central Java Province. Data retrieval is } \\
\text { done by semi-structured interviews which are then carried out by data } \\
\text { transcription. Data analysis using content analysis. In this study, there were } \\
\text { two themes, namely adaptive coping and adaptive mall coping. The results } \\
\text { of this study indicate that cancer patients need support from the closest } \\
\text { person, family and health workers to have adaptive coping during treatment. }\end{array}$ \\
\hline
\end{tabular}

\section{PENDAHULUAN}

Penyakit yang tidak mudah disembuhkan disebut penyakit kronis, kondisi ini akan menjadi bagian dari kehidupan seseorang dan cenderung berkepanjangan (Achmadi, Brahmana Askandar T, 2011).. Penyakit kronis salah satunya adalah kanker mengakibatkan pasien merasa sakit dan lemah dalam jangka waktu yang lama (World Health Organization, 2010).. Penyakit dengan jumlah kematian tertinggi kedua di dunia setelah penyakit jantung yaitu penyakit kanker (Achmadi, Brahmana Askandar T, 2011)..

Kanker menjadi penyebab kematian sekitar 8,2 juta orang pada tahun 2012. Berdasarkan data International Agency for Research on Cancer (IARC) diketahui bahwa pada tahun
2012 terdapat 14.067 .894 kasus baru kanker dan 8.201.575 kematian akibat kanker di seluruh dunia (Pusat Data dan Informasi Kementrian Kesehatan, 2012). Prevalensi penyakit kanker secara nasional pada penduduk semua umur di Indonesia tahun 2013 sebesar 1,4\% atau diperkirakan 374.792 orang. Berdasar estimasi jumlah penderita kanker Provinsi Jawa Tengah merupakan provinsi dengan estimasi penderita kanker terbanyak, yaitu sekitar 68.638 orang (InfoDatin, Pusat Data dan Informasi Kementerian Kesehatan RI., 2015) Di Jawa Tengah pasien dengan kanker serviks pada tahun 2013 sebanyak 19.734 pasien (Pusat Data dan Informasi, 2015)..

Di Kota Semarang pada tahun 2015 terdapat 310 orang, pada tahun 2016 meningkat menjadi 357 orang. Di RSUP dr Kariadi

Corresponding author:

Hernandia Distinarista

hernandia.distinarista@gmail.com

Jurnal Ilmu Keperawatan Maternitas, Vol 2 No 1, May 2019

DOI: http://dx.doi.org/10.26594/jikm.v2i1.278

e-ISSN 2621-2994 
Semarang pada tahun 2014 terdapat 141 pasien dengan kanker serviks dan meningkat menjadi 276 pasien pada tahun 2015. Populasi penderita kanker diperkirakan akan meningkat menjadi hampir 19 juta: 9,3 juta laki-laki dan 9,6 juta perempuan (Inayati, 2015).. Kemajuan pengobatan kanker dan deteksi dini kanker telah dibuktikan secara signifikan memperpanjang harapan hidup pasien hingga beberapa pasien bisa menjadi sembuh. Dalam memberikan perawatan pada pasien kanker tenaga kesehatan belum diimbangi dengan perawatan yang berkualitas tinggi untuk efek psikologis dan sosial dari kanker. Beberapa pasien kanker dan keluarga mereka melaporkan bahwa tenaga kesehatan kurang memahami kebutuhan psikososial mereka, tidak menyadari atau tidak merujuk mereka ke sumber daya yang tersedia, gagal untuk mengenali dan mengatasi depresi dan gejala lain dari stres pada pasien kanker, (Gill \& Duffy, 2010)..

Pada saat terdiagnosa kanker itu merupakan saat yang menyakitkan bagi pasien, keluarga dan orang terdekat. Hidup dengan kanker tidak hanya menjalani perawatan saja, pasien memerlukan perawatan holistik dan mendukung. Tiga perempat dari seluruh pasien kanker memerlukan dukungan psikologis dan emosional dari tenaga kesehatan, keluarga dan teman dalam berjuang untuk sembuh (American Cancer Society, 2014) (Society, n.d.).. Di Amerika Serikat hampir 14,5 juta anak-anak dan orang dewasa dengan riwayat kanker masih hidup pada tahun 2014 (Suwendar, 2013).. Ketahanan hidup untuk beberapa kanker pada orang dewasa telah meningkat, tingkat kelangsungan hidup 5 tahun secara keseluruhan $67 \%$ bagi penderita kanker dewasa (Gill \& Duffy, 2010).. Kelangsungan hidup pada pasien kanker dalam jangka panjang telah meningkat secara drastis selama beberapa dekade terakhir (Gotay \& Muraoka, 1998)..

Waktu kelangsungan hidup 5 tahun secara keseluruhan adalah 71,1\%. Kelangsungan hidup apabila dilihat pertingkatan, kelangsungan hidup pada 1 tahun adalah 94,1\%, 3 tahun adalah 79,3\%, dan 5 tahun adalah 71,1\% (Gotay \& Muraoka, 1998).. Kanker berdampak pada seluruh aspek kehidupan pasien secara fisik, psikologis maupun spiritual (Nuraeni, 2015).. Kanker tidak selalu berarti menderita dan sakit seumur hidup. Pasien yang telah sembuh dari kanker menyampaikan hal yang sebaliknya, yaitu kesejahteraan, kesehatan, dan kebahagiaan setelah sembuh dari kanker. Obat alternatif (diet, herbal, suplemen, terapi yang melibatkan tubuh, pikiran dan emosi) dan terapi komplementer memiliki peran penting dalam membantu pasien dengan kanker dalam memperpanjang hidup mereka (Chamberlain, 2011).

Optimisme berdampak positif dan memiliki efek langsung yang mempengaruhi kesejahteraan secara langsung pada pasien kanker. Pasien dengan pemikiran positif memiliki semangat juang yang tinggi untuk sembuh. Optimisme, semangat juang dan dukungan sosial memiliki pengaruh positif yang signifikan pada penderita kanker (Hodges \& Winstanley, 2012).. Pengobatan kanker yaitu serangkaian intervensi, termasuk dukungan psikososial, pembedahan, radioterapi, kemoterapi yang bertujuan menyembuhkan penyakit atau memperpanjang hidup dengan meningkatkan kualitas hidup pasien (Sweezey, 2014).. Menghadapi kanker, pasien umumnya mengadopsi dua sikap dalam menghadapi diagnosis kanker yaitu:1). Sikap aktif, dengan tujuan berjuang untuk bertahan hidup dan sehat, atau 2). Sikap pasif, pada tipe ini pasien menyerah pada keadaan dan nasib (Nidich et al., 2009)..

Hampir $70 \%$ dari pasien kanker dapat bertahan hidup 5 tahun atau lebih setelah terdiagnosis (Breitbart et al., 2012).. Pada pasien yang menderita kanker menunjukkan bahwa gaya hidup aktif: mematuhi diet yang dianjurkan, mematuhi panduan aktivitas atau olah raga dapat mengatasi masalah 
kanker dengan positif yang mempengaruhi kualitas hidup, memperpanjang kelangsungan hidup, dan mengurangi gejala penyak (Hall, Edmonds, Harding, Chochinov, \& Higginson, 2009).. Perawat memiliki peran sebagai care provider. Menunaikan perannya perawat harus melihat pasien sebagai satu kesatuan yang holistik (L.M. et al., 2012).. Perawat diharapkan berperan sebagai motivator, edukator dan mitra bagi pasien dalam menghadapi penyakitnya, sebagai penolong untuk membantu memenuhi kebutuhan pasien selama menjalani pengobatan. Sikap optimis yang diberikan perawat kepada pasien kanker memiliki kekuatan positif yang dapat meningkatkan semangat pasien dalam menjalani pengobatan dan pasien dapat sembuh dari penyakitnya (Gill \& Duffy, 2010).. Dalam merawat pasien kanker ditantang untuk memberikan perawatan holistik meliputi perawatan fisik, sosial, spiritual dan psikologis, tidak hanya bagi pasien, tetapi juga untuk keluarganya. Pasien yang baru didiagnosis, pasien dengan kekambuhan penyakit, pasien yang menerima pengobatan, dan pasien dalam tahap akhir penyakit semua membutuhkan bantuan terbesar dan mendukung bahwa perawat mungkin dapat memberikan (Doosey. Barbara Montgomery, 2013).. Peningkatan perawatan pasca perawatan dan standar perawatan pada pasien kanker sedang dikembangkan perawatan itu meliputi pemenuhan kebutuhan fisik atau medis, psikologis, sosial, spiritual, keuangan dan informasi (Albrecht \& Taylor, 2012). (Nidich et al., 2009).. Penelitian terkait kebutuhan psikologis dan fisik pada pasien kanker sehingga pasien dapat bertahan hidup dan sembuh dari penyakitnya masih terbatas, sehingga diperlukan penelitian untuk menunjang kemajuan dalam memberikan pelayanan perawatan pada pasien kanker (Rechel, Doyle, Grundy, \& Mckee, n.d.)..
Desain penelitian ini adalah penelitian kualitatif. Proses metodologi deskriptif fenomenologi meliputi empat langkah: yaitu bracketing, intuiting, analyzing, dan describing (Polit, D.F., \& Hungler, 2012). Peneliti menggali apa yang partisipan alami, rasakan, dan dilakukan terkait koping selama terdiagnosa kanker serviks. Partisipan terdiri dari 5 pasien kanker serviks. Adapun kriteria inklusi partisipan diantaranya: 1) perempuan berusia $>20$ tahun; 2) belum atau telah menikah; 3) terdiagnosa kanker serviks; 4) tidak mengalami gangguan kognitif; 5) setuju dan bersedia untuk menjadi partisipan dalam penelitian; 6) masih menjalani pengobatan; 7) tidak mengalami komplikasi.

Pada penelitian ini pengambilan data dilakukan dengan wawancara semi terstruktur, dilanjutkan dengan menuliskan hasil wawancara dalam bentuk transkrip berdasarkan hasil rekaman wawancara, selanjutnya transkrip dianalisa menggunakan content analysis. Pertanyaan yang diajukan kepada partisipan antara lain 1. Bagaimana pengalaman pasien kanker serviks sejak didiagnosa kanker? Bisa dijelaskan lagi lebih detail? 2. Bagaimana perasaan ibu ketika didiagnosis kanker serviks? 3. Bagaimana cara ibu dalam mengatasi rasa sakit atau keluhan yang ditimbulkan akibat kanker serviks? 4. Bagaimana perasaan ibu selama sakit?

\section{HASIL}

Pada bab ini peneliti memaparkan temuan penelitian yang telah dilakukan menggunakan metode dan prosedur yang telah disampaikan pada Bab III. Peneliti menyajikan data berdasar pertanyaanpertanyaan semistruktur terhadap 5 partisipan. Peneliti melakukan penelitian pertama pada Ny.N1, partisipan kedua Ny. N2 , partisipan ketiga Ny. S. Selanjutnya pada hari berikutnya peneliti melakukan penelitian pada partisipan keempat Ny. R dan partisipan kelima Ny.S.

Peneliti memperkenalkan diri terlebih dahulu sebelum melakukan wawancara, 
menjelaskan maksud dan tujuan kedatangan, menjelaskan tujuan penelitian kepada partisipan dan keluarga. Peneliti menunjukkan surat ijin penelitian dan menyampaikan point-point pertanyaan apa saja yang akan ditanyakan kepada partisipan, dan peneliti menanyakan kesediaan partisipan dengan bukti partisipan menandatangani lembar informed consent. Peneliti mempersiapkan perlengkapan wawancara seperti alat perekam yaitu berupa handphone dengan kemampuan merekam hingga 8 jam, catatan lapangan dan pedoman wawancara. Wawancara dilakukan sekitar 30-45 menit atau sesuai dengan kebutuhan.

\section{A. Kegiatan Dengan Partisipan Utama}

\section{Data Demografi Partisipan Utama}

Tabel berikut memberikan gambaran karakteristik partisipan bersumber dari form data demografi partisipan.

Tabel 4.1 Gambaran Data Demografi Partisipan Utama

\begin{tabular}{ccccccc}
\hline Inisial & $\begin{array}{c}\text { Status } \\
\text { Paritas }\end{array}$ & Usia & $\begin{array}{c}\text { Stadium } \\
\text { Kanker }\end{array}$ & $\begin{array}{c}\text { Pengobatan Yang Telah } \\
\text { Dijalani }\end{array}$ & $\begin{array}{c}\text { Pendidikan } \\
\text { Terakhir }\end{array}$ & Alamat \\
\hline P1 & 2 & 49 & 3B & $\begin{array}{c}\text { Kemoterapi, Radiasi, } \\
\text { Loading, Herbal }\end{array}$ & SD & $\begin{array}{c}\text { Karanganyar } \\
\text { Demak }\end{array}$ \\
\hline P2 & 6 & 55 & 3B & $\begin{array}{c}\text { Radiasi, Loading, } \\
\text { Kemoterapi }\end{array}$ & SD & Pecangaan Jepara \\
\hline P3 & 5 & 67 & 3B & Radiasi, bestral, loading & SD & $\begin{array}{c}\text { Gemulung } \\
\text { Jepara }\end{array}$ \\
\hline P4 & 6 & 63 & 2B & $\begin{array}{c}\text { Radiasi, Loading, } \\
\text { Kemoterapi }\end{array}$ & $\begin{array}{c}\text { Tidak tamat } \\
\text { SD }\end{array}$ & $\begin{array}{c}\text { Pager Puyung } \\
\text { Kendal }\end{array}$ \\
\hline P5 & 4 & 62 & 3B & $\begin{array}{c}\text { Radiasi, Loading, } \\
\text { Kemoterapi }\end{array}$ & SD & $\begin{array}{c}\text { Gondoarum } \\
\text { Kendal }\end{array}$ \\
\hline
\end{tabular}

Sumber: Data primer

Peneliti mendapatkan dua tema dari pasien yang didiagnosa kanker serviks. Tema tersebut mencerminkan keterkaitan antar kategori yang telah disusun dari kelompokkelompok kata kunci. Tema-tema tersebut meliputi (a) koping adaptif, dan (b) koping maladaptif pada pasien kanker serviks. Tabel berikut ini menunjukkan kata kunci, kategori, dan tema koping pasien kanker serviks.

Tabel 4.3 Kata Kunci, Kategori, dan Tema Strategi Koping Survivor Cancer Untuk Mengatasi Masalah Selama Menjalani Pengobatan Sampai Sembuh.

\begin{tabular}{|c|c|c|c|}
\hline No & Kata Kunci & Kategori & Tema \\
\hline 1. & $\begin{array}{l}\text { lunglai, sedih, menangis, khawatir, } \\
\text { tidak bisa tidur, takut, takut meninggal }\end{array}$ & Cemas & Koping maladaptif \\
\hline 2. & $\begin{array}{l}\text { Menyanyi, dibuat senang, } \\
\text { Refreshing, pijat, pergi ke pantai } \\
\text { mencari hiburan, ikut pengajian }\end{array}$ & $\begin{array}{l}\text { Distraksi } \\
\text { relaksasi }\end{array}$ & $\begin{array}{l}\text { Psikologis: koping } \\
\text { adaptif }\end{array}$ \\
\hline 3. & $\begin{array}{l}\text { Mencari cara bagaimana caranya bisa sembuh, } \\
\text { berharap, tidak putus asa, semangat ingin hidup, } \\
\text { ingin sembuh, memotivasi diri, semangat, } \\
\text { berusaha hidup sehat, berusaha tidak sedih, } \\
\text { berusaha senang, tidak apa-apa tidak cemas, tidak } \\
\text { pernah marah }\end{array}$ & Semangat & \\
\hline
\end{tabular}

Sumber : Data Primer Hasil Wawancara 


\section{Pembahasan}

Pembahasan dalam Bab 5 ini memaparkan temuan peneliti berdasarkan hasil wawancara dan observasi, kemudian dibandingkan dengan jurnal dan artikel yang berkaitan dengan topik penelitian, literature tentang koping pada pasien kanker serviks. Bab ini menyajikan implikasi hasil penelitian dalam keperawatan dan keterbatasan yang dihadapi peneliti selama melakukan proses pengambilan data hingga analisis data. Berdasarkan hasil penelitian telah diidentifikasi menjadi dua tema, tema-tema berikut menggambarkan koping pasien kanker serviks.

Metode yang digunakan oleh Lazarus dan Folkman berdasarkan pada upaya spesifik, baik adaptasi perilaku dan psikologis, yang digunakan orang untuk menguasai, mentolerir, mengurangi, atau meminimalkan peristiwa yang membuat stres. Metode mereka sangat jelas; mereka telah membedakan antara dua strategi koping umum: strategi penyelesaian masalah yaitu upaya untuk melakukan sesuatu untuk meringankan keadaan yang penuh tekanan, sedangkan strategi koping yang berfokus pada emosi melibatkan upaya untuk mengatur konsekuensi emosional dari peristiwa yang berpotensi menimbulkan stres atau yang berpotensi menimbulkan stres. (Baqutayan, 2015). Penelitian koping pasien kanker serviks didapatkan hasil dua tema, terbagi dalam tiga kategori berikut:

\section{Koping maladaptif}

\section{a. Cemas}

\footnotetext{
"Hati saya sedih mbak, lunglai. Bagaimana caranya biar bisa sembuh ..... sedih, menangis mbak. khawatir saya, bagaimana kalau saya gundul ... (P1)

“ ... waktu itu banyak orang menyampaikan tentang kanker serviks ini dapat membuat meninggal ya saya khawatir dan takut mati, waktu itu saya masih muda, anak saya banyak, sedih harus bagaimana tidak tahu .... kalau
}

berpikir tentang sakit kanker ini baru bisa tidur sampai jam 3 pagi “ (P2)

“... saya meminta anak-anak membawa
saya ke rumah sakit yang bagus, khawatir
mbak .... sampai tinggi tensi saya karena
takut ...." (P3)

Diagnosis kanker tidak hanya mempengaruhi pasien tetapi juga keluarga dan teman dekat. Pasien dengan kanker mungkin merasa takut, atau marah tentang perubahan yang tidak diinginkan dalam hidupnya. Pasien mungkin merasa mati rasa atau bingung, mengalami kesulitan mendengarkan, memahami, atau mengingat apa yang orang katakan, terutama ketika dokter pertama kali memberi tahu bahwa pasien menderita kanker. Tidak jarang orang cemas, stress begitu mereka mendengar kata "kanker". (Manuel, Roth, Keefe, \& Brantley, 1987).

Setelah dokter menyampaikan diagnosis kanker, pasien mungkin merasa syok, tidak percaya, takut, cemas, bersalah, sedih, sedih, depresi, marah, dan banyak lagi. Setiap orang mungkin memiliki beberapa atau semua perasaan ini, dan masing-masing akan menanganinya dengan cara yang berbeda. Tidak ada yang pernah siap mendengar bahwa mereka mengidap kanker. (Mary Ann Hoffman, Lent, \& RaqueBogdan, 2012)..

Untuk mengurangi cemas pada pasien kanker berikut kiat-kiat agar membantu pasien selama menjalani perawatannya: 1) Membuat daftar pertanyaan untuk diajukan kepada tim perawatan kesehatan; 2) Didampingi anggota keluarga atau teman selama perawatan; 3) Menanyakan apakah anda dapat merekam percakapan penting yang disampaikan tenaga kesehatan; 4) Membuat catatan; 5) Minta tim perawatan kesehatan anda untuk menjelaskan apa pun yang anda tidak mengerti (Man, Unit, \& Hospital, 2009). 
2. Psikologis: koping adaptif

\section{a. Semangat}

“ ... saya semangat hidup, dan memiliki harapan hidup mbak. Saya menanyakan ke anak-anak bagaimana caranya saya bisa sembuh. ... saya berusaha tidak putus asa mbak, masih semangat ingin hidup, dan ingin sembuh. .... saya juga berusaha memotivasi diri saya sendiri “ (P1)

"saya menyemangati diri sendiri ....memotivasi diri agar sehat ... " (P2)

“... berusaha semangat ingin sehat mbak. Walau keadaannya mungkin seperti ini, terkadang saya ingin mati itu tidak, tetapi saya berusaha minta ke Allah ingin sembuh. Dengan diberi Allah kesehatan besok saya ingin memperbaiki ibadah saya...." (P3)

“... saya berusaha tidak sedih mbak, biasa saja. Saya senang kalau membayangkan bisa sembuh..... selama sakit saya berusaha tenang mbak, berusaha tetap semangat karena ingin sembuh mbak ...." (P4)

" saya berusaha tidak khawatir mbak, lillahi ta'ala .... jangan suka marah, anak dan keluarga menghibur jadi saya senang" (P5)

Pada pasien kanker serviks dengan stimulus yang sama akan menyebabkan respons koping yang berbeda pada individu yang berbeda. Pasien dengan kanker dan keluarga mereka sering menghadapi tekanan besar dan menggunakan banyak pendekatan yang berbeda untuk mengurangi tekanan emosional. Setiap individu melakukan perjalanan hidup yang unik. Setiap orang merespons secara berbeda terhadap kesulitan dan berupaya dengan caranya masingmasing. Untuk pasien yang didiagnosis dengan kanker, empat respons psikologis primer telah diidentifikasi yang dapat dikelompokkan ke dalam empat tema: 1). penolakan; 2). semangat juang; 3). penerimaan; 4). Keputusasaan (M A Hoffman, Lent, \& Raque-Bogdan, 2013)..
Koping yang berfokus untuk mengatasi stressor pada penderita kanker, dapat dimulai dengan mencari diagnosis, mengumpulkan informasi, mencari pendapat kedua, dan membuat keputusan pengobatan. Penanganan yang berfokus pada emosi ditujukan untuk mengelola aspek internal stresor dan dapat mencakup menjauhkan atau mengalihkan keluhan yang dialami secara positif (Albrecht \& Taylor, 2012)..

Beberapa pasien kanker berusaha keras untuk menemukan faktor yang sesuai untuk mendukung keseimbangan lahir batin mereka, semuanya untuk menjaga jarak kematian yang tersembunyi dan menjaga hubungan mereka dengan kehidupan. Faktor yang mempengaruhi adalah kebersamaan, keterlibatan, harapan, kelanjutan, dan faktor ini berfungsi sebagai perisai terhadap perasaan menyakitkan terkait dengan kematian pasien yang akan dating (Manuel et al., 2014).

Beberapa pasien menemukan cara lebih mudah untuk menghadapi kenyataan dalam menghadapi penyakit kompleks seperti kanker. Sering kali ada ketakutan besar akan hal yang tidak diketahui dan tidak pasti tentang apa yang akan terjadi. Pengetahuan dapat membantu mengurangi rasa takut akan hal yang tidak diketahui. Pasien dan keluarga dengan kanker dapat belajar banyak tentang jenis kanker yang dimiliki, perawatannya, dan apa yang dapat pasien harapkan. (Mary Ann Hoffman et al., 2012).

\section{b. Relaksasi Distraksi}

"berusaha mengalihkan perhatian, saya nyanyi-nyanyi saya berusaha menyemangati diri sendiri .... " (P2) 
“.... refreshing, saya diajak anak-anak main ke pantai, dibuat senang hatinya .... anakanak memijit saya..." (P3)

“ .... banyak mencari hiburan misal, ikut pengajian dan jalan-jalan...." (P5)

Menurut Lazarus dan Folkman, koping yang berfokus pada masalah termasuk koping yang konfrontatif, mencari dukungan sosial, merencanakan pemecahan masalah seutuhnya, dan mencari dukungan sosial. Sedangkan koping yang berfokus pada emosi meliputi kontrol diri, mencari dukungan sosial, menjauhkan, penilaian positif, menerima tanggung jawab, dan menghindar (Achmadi, Brahmana Askandar T, 2011)..

Merasa sedih sepanjang waktu, sulit tidur, atau putus asa adalah tanda bahwa pasien memerlukan bantuan profesional, tanda-tanda lain adalah perasaan panik, cemas, atau menangis terus-menerus. Jika pasien merasa perlu bantuan profesional, bicarakan dengan dokter atau perawat. (Chamberlain, 2011)..

Hal-hal lain yang dapat pasien kanker lakukan untuk membantu mengatasi emosi Anda: 1) Minta dukungan dari keluarga, teman, dan tenaga kesehatan akan sangat membantu; 2) Dapatkan dukungan spiritual melalui doa, meditasi, atau latihan lain yang membantu anda merasa lebih tenang; 3) Perhatikan kebutuhan fisik: istirahat dan nutrisi; 4) Temukan cara untuk mengekspresikan perasaan anda, seperti bercerita, mendengarkan musik, melukis, atau menulis; 5) Berjalan atau berolahraga, pastikan untuk berdiskusi dengan tenaga kesehatan terkait aktivitas olahraga yang akan dijalani; 6) mencari informasi tentang penyakit kanker dan perawatannya; 7) Konsultasikan tentang gaya hidup sehat. (Mary Ann Hoffman et al., 2012).

\section{REFERENSI}

Achmadi, Brahmana Askandar T, S. (2011). Karakteristik Penderita Kanker Serviks 20062010 di RSUD dr. Soetomo. Majalah Obstetri \& Ginekologi, 18, 128-133.

ACS. (2014). The History of Cancer. ACS-American Cancer Society, 1-16. https://doi.org/10.1038/nrc1279

Albrecht, T. A., \& Taylor, A. G. (2012). Physical activity in patients with advanced-stage cancer: A systematic review of the literature. Clinical Journal of Oncology Nursing, 16(3), 293-300. https://doi.org/10.1188/12.CJON.293-300

Baqutayan, S. M. S. (2015). Stress and Coping Mechanisms: A Historical Overview. Mediterranean Journal of Social Sciences, 6(2), 479-488. https://doi.org/10.5901/mjss.2015.v6n2s1p4 79

Breitbart, W., Poppito, S., Rosenfeld, B., Vickers, A. J., Li, Y., Abbey, J., ... Cassileth, B. R. (2012). Pilot randomized controlled trial of individual meaning-centered psychotherapy for patients with advanced cancer. Journal of Clinical Oncology, 30(12), 1304-1309. https://doi.org/10.1200/JC0.2011.36.2517

Chamberlain, J. (2011). Cancer Survivors 'Stories They did it. You can too! Long Island Press.

Doosey. Barbara Montgomery, K. L. (2013). Holistic Nursing A Handbook for Practice (Six; H. M. Barrere. Cynthia C, Ed.). Burlington: Kevin Sullivan.

Gill, F., \& Duffy, A. (2010). Caring For Cancer Patient On Non - Specialist Wards. British Journal of Nursing, 19(12), 761-767.

Gotay, C., \& Muraoka, M. (1998). Quality of Life in Long-Term Survivors of Adult-Onset Cancers. Journal of the National Cancer Institute, 90(9), 656-667. https://doi.org/10.1093/jnci/90.9.656

Hall, S., Edmonds, P., Harding, R., Chochinov, H., \& Higginson, I. J. (2009). Assessing the feasibility, acceptability and potential effectiveness of Dignity Therapy for people with advanced cancer referred to a hospital-based palliative care team: Study protocol. BMC Palliative Care, 8, 5. https://doi.org/10.1186/1472-684X-8-5

Hodges, K., \& Winstanley, S. (2012). Effects of 
optimism, social support, fighting spirit, cancer worry and internal health locus of control on positive affect in cancer survivors: A path analysis. Stress and Health, 28(5), 408-415. https://doi.org/10.1002/smi.2471

Hoffman, M A, Lent, R. W., \& Raque-Bogdan, T. L. (2013). A Social Cognitive Perspective on Coping With Cancer: Theory, Research, and Intervention. Counseling Psychologist, 41(2), 240-267.

https://doi.org/10.1177/0011000012461378

Hoffman, Mary Ann, Lent, R. W., \& Raque-Bogdan, T. L. (2012). A Social Cognitive Perspective on Coping With Cancer. The Counseling Psychologist, 41(2), 240-267. https://doi.org/10.1177/0011000012461378

Inayati, K. (2015). Analisis Survival Nonparametrik Pada Pasien Menggunakan Metode Kaplan Meier dan Uji Log Rank. JURNAL SAINS DAN SENI ITS, 4(2), 199-204.

InfoDatin.Pusat Data dan Informasi Kementerian Kesehatan RI. (2015). Stop Kanker.

L.M., B., J.G.Z., van U., I.I., R., J., B., W., van M., \& W.J., B. (2012). Physical and psychosocial benefits of yoga in cancer patients and survivors, a systematic review and meta-analysis of randomized controlled trials. BMC Cancer, 12(1), no pagination. https://doi.org/10.1186/1471-2407-12-559

Man, L. W., Unit, P. C., \& Hospital, H. (2009). Coping Strategies in the Face of Death. Strategies, (2), 28-32.

Manuel, G. M., Roth, S., Keefe, F. J., \& Brantley, B. A. (1987). Coping with cancer. Journal of Human Stress, 13(4), 149-158. https://doi.org/10.1080/0097840X.1987.9936
808

Nidich, S. I., Fields, J. Z., Rainforth, M. V, Pomerantz, R., Cella, D., Kristeller, J., ... Schneider, R. H. (2009). A Randomized Controlled Trial of the Effects of Transcendental Meditation on Quality of Life in Older Breast Cancer Patients. (August 2003). https://doi.org/10.1177/1534735409343000

Nuraeni, A. (2015). Spiritual Needs of Patient With Cancer.

Pusat Data dan Informasi. (2015). Buletin Jendela Data dan Informasi Kesehatan (Situasi Penyakit Kanker). Bakti Husada, ISSN 2088-270X.

Pusat data dan informasi kementrian kesehatan, R. (2012). Situasi penyakit kanker 4.

Rechel, B., Doyle, Y., Grundy, E., \& Mckee, M. (n.d.). Health Systems And Policy Analysis Policy Brief 10 How can health systems respond to population ageing?

Society, A. C. (n.d.). Life after Treatment The Next Chapter in Your Survivorship Journey.

Suwendar. (2013). Analisis Outcome Humanistik Pada Pasien Kanker Serviks Rawat Inap Selama Menjalani Kemoterapi Di Rumah Sakit Umum Pusat Dr.Hasan Sadikin Bandung Dengan Menggunakan Kuesioner EORTC QLQ-C30 Versi 3. 169-174.

Sweezey, N. (2014). Cancer The Problem ( 1 ): prematurity.

World Health Organization. (2010). Global status report on noncommunicable diseases 2010. World Health Organization, 176. https://doi.org/9789241564229 